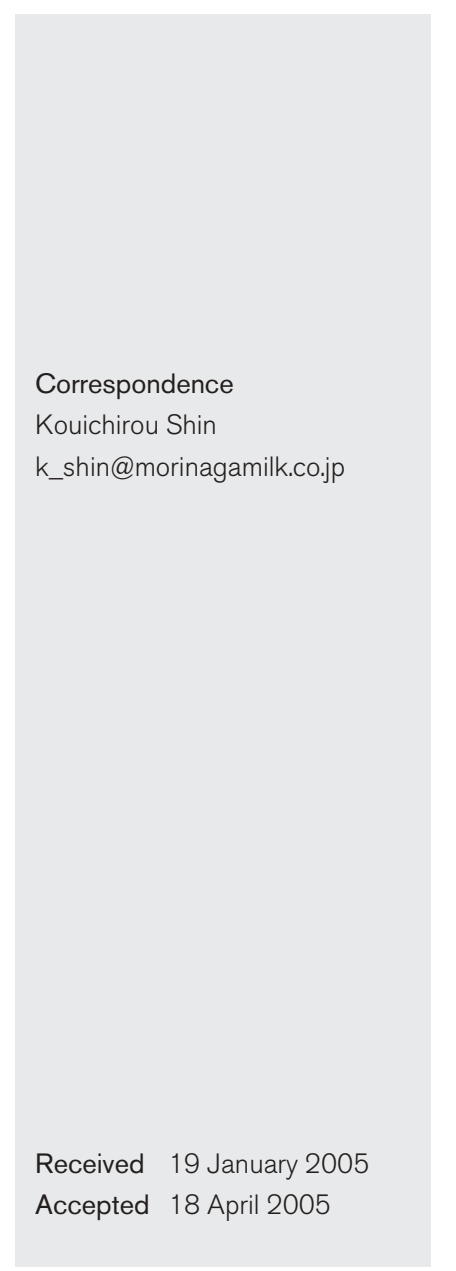

\title{
Effects of orally administered bovine lactoferrin and lactoperoxidase on influenza virus infection in mice
}

\author{
Kouichirou Shin, ${ }^{1,2}$ Hiroyuki Wakabayashi, ${ }^{1,2}$ Koji Yamauchi, ${ }^{1}$ \\ Susumu Teraguchi, ${ }^{1}$ Yoshitaka Tamura, ${ }^{1}$ Masahiko Kurokawa ${ }^{2} \dagger$ \\ and Kimiyasu Shiraki \\ ${ }^{1}$ Nutritional Science Laboratory, Morinaga Milk Industry Co. Ltd, 5-1-83 Higashihara, Zama, \\ Kanagawa 228-8583, Japan \\ ${ }^{2}$ Department of Virology, Toyama Medical and Pharmaceutical University, 2630 Sugitani, Toyama, \\ Toyama 930-0194, Japan
}

\begin{abstract}
Milk contains a wide variety of host protective factors against infectious microbes. Among these protective factors, lactoferrin (LF) and lactoperoxidase (LPO) have been reported to exhibit antiviral activities as well as immuno-modulatory effects. In the present study, the effects of orally administered LF and LPO were assessed in a mouse influenza virus infection model. BALB/c mice were intranasally infected with $6.6 \times 10^{2}$ p.f.u. of influenza virus $A / P R / 8 / 34(\mathrm{H} 1 \mathrm{~N} 1)$. Bovine $L F$ or LPO was administered once daily at a dose of $62.5 \mathrm{mg}$ per mouse by gavage, starting 1 day before infection. Mice given LF or LPO showed a significantly lower lung consolidation score on day 6 after infection compared with the control mice that were given water instead. Concurrently, the number of infiltrated leukocytes recovered from bronchoalveolar lavage fluid (BALF) on day 6 was significantly lower in mice given LF or LPO. However, the virus yield in the BALF was not affected by these treatments. The serum level of IL-6, a pro-inflammatory cytokine, positively correlated with the lung consolidation score in each group and was significantly lower on day 6 in the mice given LPO. These results suggest the potential of oral administration of LF or LPO to attenuate pneumonia in influenzavirus-infected mice through the suppression of infiltration of inflammatory cells in the lung.
\end{abstract}

\section{INTRODUCTION}

Influenza virus infects the upper respiratory tract of humans and induces a variety of symptoms such as nasal secretions, cough, headache and fever (Kaiser et al., 2001; Mogensen \& Paludan, 2001). In addition to the direct cytopathic effect, the involvement of host immune responses has been suggested in the pathogenesis of influenza virus infection (Maeda \& Akaike, 1991; Mogensen \& Paludan, 2001). In humans, the symptoms of influenza virus infection have been revealed to correlate with elevated levels of local and systemic pro-inflammatory cytokines, including tumour necrosis factor (TNF)- $\alpha$ and interleukin (IL)-6 (Kaiser et al., 2001). In mice, experimental intranasal infection with influenza virus causes deadly pneumonia with an elevated production of pro-inflammatory cytokines (Conn et al., 1995; Mori et al., 1999; Tsurita et al., 2001) and infiltration of inflammatory

†Present address: Department of Pharmacology, Kyushu University of Health and Welfare, 1714-1 Yoshino-Machi, Nobeoka, Miyazaki 8828508, Japan.

Abbreviations: BALF, bronchoalveolar lavage fluid; IL, interleukin; LF, lactoferrin; LPO, lactoperoxidase; TNF, tumour necrosis factor. cells (Maeda \& Akaike, 1991; Hashiba et al., 2001; Tsurita et al., 2001; Deliyannis et al., 2002).

Lactoferrin (LF), an iron-binding glycoprotein of the transferrin family, and lactoperoxidase (LPO), a haem-containing glycoprotein of the mammalian peroxidase family, are components of milk, saliva, airway mucus and other exocrine secretions. These proteins have a wide range of biological functions including antimicrobial and immuno-modulatory effects (Lönnerdal \& Iyer, 1995; Vorland, 1999; Hooijdonk et al., 2000; Conner et al., 2002). LF exhibits inhibitory activity against various viruses, including cytomegalovirus, herpes simplex virus-1 (HSV-1), human immunodeficiency virus (HIV), hepatitis B and C viruses, poliovirus and respiratory syncytial virus (RSV), by preventing entry of the viruses into the host cells (van der Strate et al., 2001). LPO, in combination with its physiological substrates hydrogen peroxide $\left(\mathrm{H}_{2} \mathrm{O}_{2}\right)$ and thiocyanate $\left(\mathrm{SCN}^{-}\right)$, displays a wide spectrum of virucidal activity against HIV, HSV-1, RSV and echovirus (Pourtois et al., 1990; Mikola et al., 1995).

The protective effects of orally administered LF against bacterial, fungal and viral infections have been recently demonstrated in animals as well as in humans (Tanaka $e t$ 
al., 1999; Haversen et al., 2000; Hooijdonk et al., 2000; Yamauchi et al., 2000; Di Mario et al., 2003; Takakura et al., 2004; Wakabayashi et al., 2004). The contribution of immuno-modulatory properties besides direct antimicrobial actions has been suggested for many of these protective effects of orally administered LF (Haversen et al., 2000; Yamauchi et al., 2000; Ishii et al., 2003; Takakura et al., 2004; Wakabayashi et al., 2004). Thus far, studies on the effects of orally administered LPO have been limited to direct antimicrobial effects in the oral cavity and gastrointestinal tract (Reiter et al., 1980; Hooijdonk et al., 2000; Tenovuo, 2002). LPO inhibits the production of IFN- $\gamma$ from mitogenstimulated sheep lymphocytes in vitro (Wong et al., 1997), whereas subcutaneously injected LPO elevates the level of IFN- $\gamma$ in the local lymph fluid of sheep (Wong et al., 1996). LPO stimulates functions of macrophages including respiratory burst, cytotoxicity and TNF production in vitro (Lefkowitz et al., 1988, 1990), although the physiological significance of these immuno-modulatory properties of LPO is currently unclear.

In this study, we investigated the protective effects of LF and LPO as potential antiviral and/or immuno-modulating compounds in a well-established murine model of influenza virus infection where these milk components were administered via the oral route.

\section{METHODS}

Virus. Influenza virus A/PR/8/34(H1N1), adapted to the mice, was used throughout the experiments. The influenza virus was propagated in the lungs of mice and a stock solution of the virus was prepared as previously described (Tsurita et al., 2001). Virus titres in the stock solution were determined by the method described in the plaque assay section below.

Compounds. LF purified from bovine milk was produced by Morinaga Milk Industry. LPO purified from bovine milk was purchased from Biopole.

Animals. Specific-pathogen-free female BALB/c mice (6 weeks old) were obtained from Nihon SLC. Five to six mice were housed in a plastic cage with a stainless steel sieve placed inside to prevent coprophagy, and were kept in a room with a controlled temperature $\left(23 \pm 2{ }^{\circ} \mathrm{C}\right)$ and light-dark cycle (12 h each). They were fed a standard pellet diet CE-2 (Clea) and water ad libitum. The animals were acclimatized to the new environment for 7 days before the experiments. The animal experimentation guidelines of Toyama Medical and Pharmaceutical University were followed in the animal studies.

Influenza virus infection model of mice. Mice were anaesthetized with an intraperitoneal injection of sodium pentobarbital at a dose of $0.9 \mathrm{mg}$ per mouse and intranasally infected with $10 \mu \mathrm{l}$ PBS containing $6.6 \times 10^{2}$ p.f.u. influenza virus. We observed that infection with this dose of the influenza virus resulted in no dead mice by day 6 after infection, but a 20 to $40 \%$ mortality by day 14 . LF or LPO was dissolved in purified water at a concentration of $12.5 \%(\mathrm{w} / \mathrm{v})$ and $0.5 \mathrm{ml}$ of the solution per mouse was orally administered once daily by gavage (62.5 mg per mouse). As a control, mice were given an equal volume of water instead. Oral administration began 1 day before infection and continued until 1 day before sacrifice. The body weights of the mice were monitored daily.
In experiment 1 , the effects of orally administered LF or LPO were examined by comparison with the control mice given water using a total of 18 animals for each experimental group. Six mice of each group were sacrificed on day 0 , before infection, and on days 4 and 6 after infection. Blood was drawn by orbital puncture under pentobarbital anaesthesia. Bronchoalveolar lavage fluid (BALF) was obtained by instilling $1 \mathrm{ml}$ of Eagle's minimal essential medium into the lungs and aspirating it from the trachea of mice three times using a tracheal cannula. After the lavage, an entire lung was removed and assigned a score of pneumonia depending on the surface area of consolidation (Sidwell et al., 1996) that ranged from 0 (normal) to 10 (entire consolidation). In detail, each of five lung lobes was separately scored depending on its surface area of consolidation, as indicated by plum colouration, as follows: 0 , normal lung; $1, \leqslant 50 \%$ consolidation; $2,>50 \%$ consolidation. The scores of the five lobes were then summed to give a lung consolidation score for each mouse. Comparable scores of the lung consolidation were obtained from two independent observers in our preliminary experiment. Blood samples were left for $1 \mathrm{~h}$ at room temperature and centrifuged at $500 \mathrm{~g}$ for $10 \mathrm{~min}$ to prepare the serum. Serum was stored at $-80{ }^{\circ} \mathrm{C}$ until cytokine analysis.

In experiment 2, the effect of orally administered LF on the lung consolidation score was re-examined in the mice on day 6 after infection by comparing the mice given LF with the control mice that were given water. Twenty animals were used for each experimental group in experiment 2 .

Infiltrated cells. The BALF was centrifuged at $500 \mathrm{~g}$ for $10 \mathrm{~min}$, and the cells and supernatants were separately collected. The cells infiltrated in the BALF were dispersed in the original volume of PBS and the total number was determined after erythrocyte lysis using the automatic haematocytometer Celltac MEK-5254 (Nihon Kohden). The cells infiltrated in the BALF were also stained with Diff-Quick (International Reagents) and the contents of the macrophages, neutrophils and lymphocytes were differentially determined under the microscope depending on their morphology, as described elsewhere (Hashiba et al., 2001). The numbers of these different types of leukocytes were calculated from their ratio and the total cell number. The supernatant was stored at $-80^{\circ} \mathrm{C}$ until analysis of the virus titre and cytokine levels.

Plaque assay. Virus titres in the supernatant of the BALF were determined with the plaque assay, as described elsewhere (Kurokawa et al., 1990). Briefly, confluent monolayers of Madin-Darby canine kidney cells were incubated with the supernatant of BALF serially diluted in PBS containing $1 \%$ bovine serum albumin for $1 \mathrm{~h}$ at room temperature. The cells were then overlaid with Eagle's minimal essential medium supplemented with $0 \cdot 2 \%$ bovine serum albumin, $0 \cdot 1 \%$ DEAE Dextran, $1 \mu \mathrm{g}$ trypsin $\mathrm{ml}^{-1}$ and $0.8 \%$ agar, and maintained in a humidified atmosphere containing $5 \% \mathrm{CO}_{2}$ for 3 days. The agar media were then removed and the cells were fixed with $5 \%$ formalin solution and stained with $0.03 \%$ methylene blue solution. Visualized plaques were counted and the virus titre was expressed as $\log _{10}$ p.f.u. $\mathrm{ml}^{-1}$.

Cytokine assay. The concentrations of IFN- $\gamma$, IL-12 and IL- 6 in the supernatant of BALF and IL- 6 in serum were determined by using ELISA kits (Amersham Biosciences) according to the manufacturer's instructions.

Statistical analysis. Results were analysed statistically with one-way ANOVA, followed by the multiple-range Tukey-HSD test. The Pearson correlation was used to determine the association. KaleidaGraph Version 3.6 for Windows (Synergy Software) and StatView Version 5.0 for Windows (SAS Institute) were used to perform the analyses. Data were expressed as mean \pm SD. 


\section{RESULTS AND DISCUSSION}

\section{Effects of LF and LPO on body weight loss and lung consolidation}

The time-course for body weight changes of the influenzavirus-infected mice in experiment 1 is shown in Fig. 1. There was no significant difference in body weight loss between the mice given LF and the control mice. Mice given LPO showed significantly less body weight loss on day 6 after infection compared with the control mice $(P=0.035)$.

Table 1 shows the effects of LF and LPO on the lung consolidation score in the influenza-virus-infected mice. In experiment 1 , the consolidation score of the control mice was higher on day 6 than that on day 4 . No significant difference in consolidation score was detected between mice given LF $(3 \cdot 2 \pm 2 \cdot 2)$ and the control mice $(5 \cdot 0 \pm 1 \cdot 1)$ using six animals per group on days 4 or 6 , although the mean score was lower in the mice given LF. We re-examined the effect of LF on the consolidation score using larger numbers of animals in experiment 2 (20 animals per group). A significantly lower consolidation score was observed in the mice

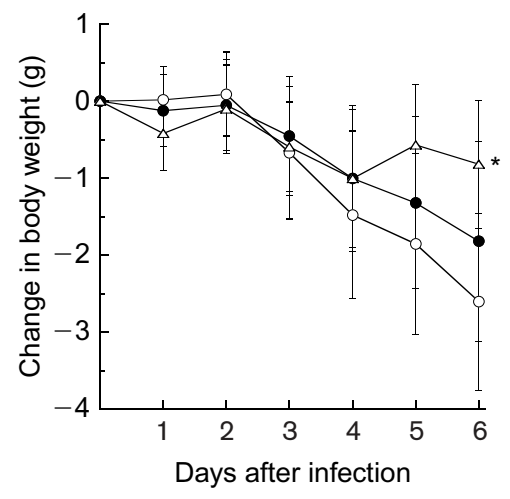

Fig. 1. Effects of orally administered LF and LPO on the body weight of influenza-virus-infected mice. Water $(\bigcirc)$, LF $(\bullet)$ or LPO $(\triangle)$ was administered once daily from 1 day before infection until 5 days after infection. The data represent the mean \pm SD of 12 mice until 4 days after infection and six mice from 5 days after infection in experiment 1. ${ }^{*} P<0.05$ vs water control. given LF compared with the control mice in experiment 2 $(P=0 \cdot 040)$. Mice given LPO showed a significantly lower consolidation score on day 6 compared with the control mice in experiment 1 using six animals per group $(P=0 \cdot 020)$. The reproducibility of the result of LPO administration was confirmed in another experiment (details not shown).

\section{Effects of LF and LPO on virus yield in BALF}

Because the lavage fluids of respiratory tracts and pulmonary alveoli have been often used to assess the virus titre in influenza-virus-infected humans and experimental animals (Mori et al., 1999; Kaiser et al., 2001; Tsurita et al., 2001), we compared the virus yield in the BALF of influenza-virusinfected mice. The virus yield in the BALF of the control mice declined over the time-course on days 4-6 (Fig. 2). No effect of orally administered LF or LPO was observed on the virus yield on either day 4 or day 6 .

It has been reported that LF inhibits the influenza-virusinduced haemagglutination of red blood cells, mimicking the receptor-mediated viral attachment in the earliest step of infection, at MICs ranging from 16 to $128 \mu \mathrm{g} \mathrm{ml}^{-1}$ depending on the strain (Kawasaki et al., 1993). In our preliminary

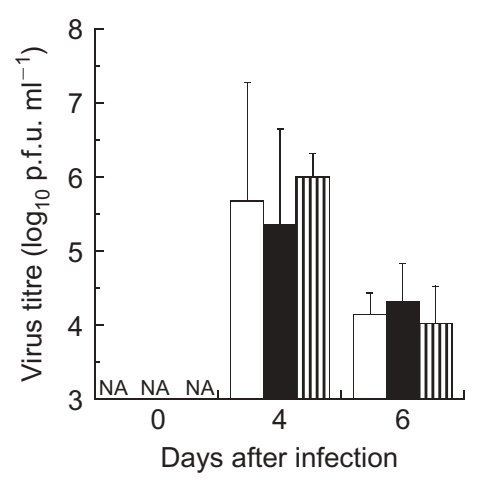

Fig. 2. Virus yield in the BALF of influenza-virus-infected mice. Water (open bars), LF (filled bars) or LPO (striped bars) was administered once daily from 1 day before infection until 1 day before sacrifice. The data represent the mean virus titre \pm SD of six mice in experiment 1 . NA, not assayed.

Table 1. Effects of LF and LPO on the lung consolidation score of influenza-virus-infected mice

\begin{tabular}{|cccccc|}
\hline Experiment & $\begin{array}{c}\text { Days after } \\
\text { infection }\end{array}$ & $\begin{array}{c}\text { No. of animals } \\
\text { in each group }\end{array}$ & \multicolumn{2}{c|}{ Lung consolidation score (mean \pm SD) } \\
\cline { 4 - 6 } & & & Water & LF & LPO \\
\hline 1 & 0 & 6 & $0 \cdot 0$ & $0 \cdot 0$ & $0 \cdot 0$ \\
& 6 & 6 & $1 \cdot 3 \pm 1 \cdot 2$ & $1 \cdot 3 \pm 1 \cdot 2$ & $1 \cdot 2 \pm 0 \cdot 8$ \\
& 6 & 20 & $3 \cdot 0 \pm 1 \cdot 1$ & $3 \cdot 2 \pm 2 \cdot 2$ & $1 \cdot 8 \pm 1 \cdot 8^{*}$ \\
2 & 6 & $3 \cdot 8 \pm 2 \cdot 1$ & $2 \cdot 4 \pm 2 \cdot 0^{*}$ & $\mathrm{NA}$ \\
\hline
\end{tabular}

NA, Not administered.

${ }^{\star} P<0 \cdot 05$ vs water control. 
in vitro experiment, LPO combined with $\mathrm{H}_{2} \mathrm{O}_{2}$ and $\mathrm{SCN}^{-}$ showed virucidal activity against the influenza virus $(8 \mu \mathrm{g}$ LPO ml ${ }^{-1}, 0.6 \mathrm{mM} \mathrm{H}_{2} \mathrm{O}_{2}$ and $0.66 \mathrm{mM} \mathrm{NaSCN}$, details not shown). One possible reason behind the lack of effect of orally administered LF and LPO on the virus yield regardless of having antiviral activities in vitro is that these proteins were not effectively absorbed from the intestine into circulation and therefore did not exhibit direct antiviral effects in vivo in the respiratory system. The serum levels of bovine LF and LPO by ELISA determination were very low in the groups of mice given these respective proteins on day 6 (mice given LF, $7 \cdot 2 \pm 6 \cdot 0 \mathrm{ng} \mathrm{ml}^{-1}$; mice given LPO, $2 \cdot 4 \pm 2 \cdot 4 \mathrm{ng} \mathrm{ml}^{-1}$ ), whereas neither LF nor LPO was detectable in the control mice (details not shown).

\section{Effects of LF and LPO on number of infiltrated cells in BALF}

The total number of infiltrated cells in the BALF markedly increased after influenza virus infection in all groups (Fig. $3 a)$. In the control mice, the total number of cells increased in a time-dependent manner until day 6 after infection. No significant difference in the total numbers of cells was observed among the groups on day 4 . However, mice given LF and LPO showed significantly lower total numbers of cells than the control mice on day $6(P=0.004$ and $0 \cdot 003$, respectively). Analysis of the composition of the infiltrated cells in the BALF revealed that influenza virus infection resulted in a marked increase in macrophages (Fig. 3b), neutrophils (Fig. 3c) and lymphocytes (Fig. 3d). Mice given LPO tended to have lower numbers of macrophages on day 4 than the control mice $(P=0 \cdot 058)$. Mice given LF or LPO showed significantly lower numbers of macrophages on day 6 compared with the control mice $(P=0.041$ and $0 \cdot 009$, respectively), but not on day 4 . Mice given LPO tended to have higher numbers of neutrophils on day 4 compared with the control mice $(P=0 \cdot 086)$. On day 6 , the numbers of neutrophils were significantly lower in the mice given LF compared with the control mice $(P=0 \cdot 041)$. No significant difference in the numbers of lymphocytes was observed among the groups on both days 4 and 6 . The reduction of infiltrated leukocytes on day 6 was consistent with the reduction in the lung consolidation score due to the administration of LF and LPO.

Influenza virus infection induces the innate immune response of macrophages and neutrophils, followed by the infiltration of virus-specific cytotoxic T lymphocytes (Hashiba et al., 2001; Deliyannis et al., 2002). Although these immune responses are important for viral clearance, it has been reported that a hyper-reaction of the host immune system is involved in the pathogenesis of pneumonia caused by the influenza virus (Maeda \& Akaike, 1991; Hashiba et al., 2001). In the current study, the suppression of the infiltrated inflammatory cells due to the administration of LF and LPO was consistent with the reduction in the lung consolidation score. These findings suggest that LF and LPO suppress the hyper-reaction of the host immune system against influenza virus infection and therefore attenuate the pneumonia. Another important finding is that the administration of LF and LPO exerted no effect on virus replication (Fig. 2), indicating that the potency of the antiviral protective
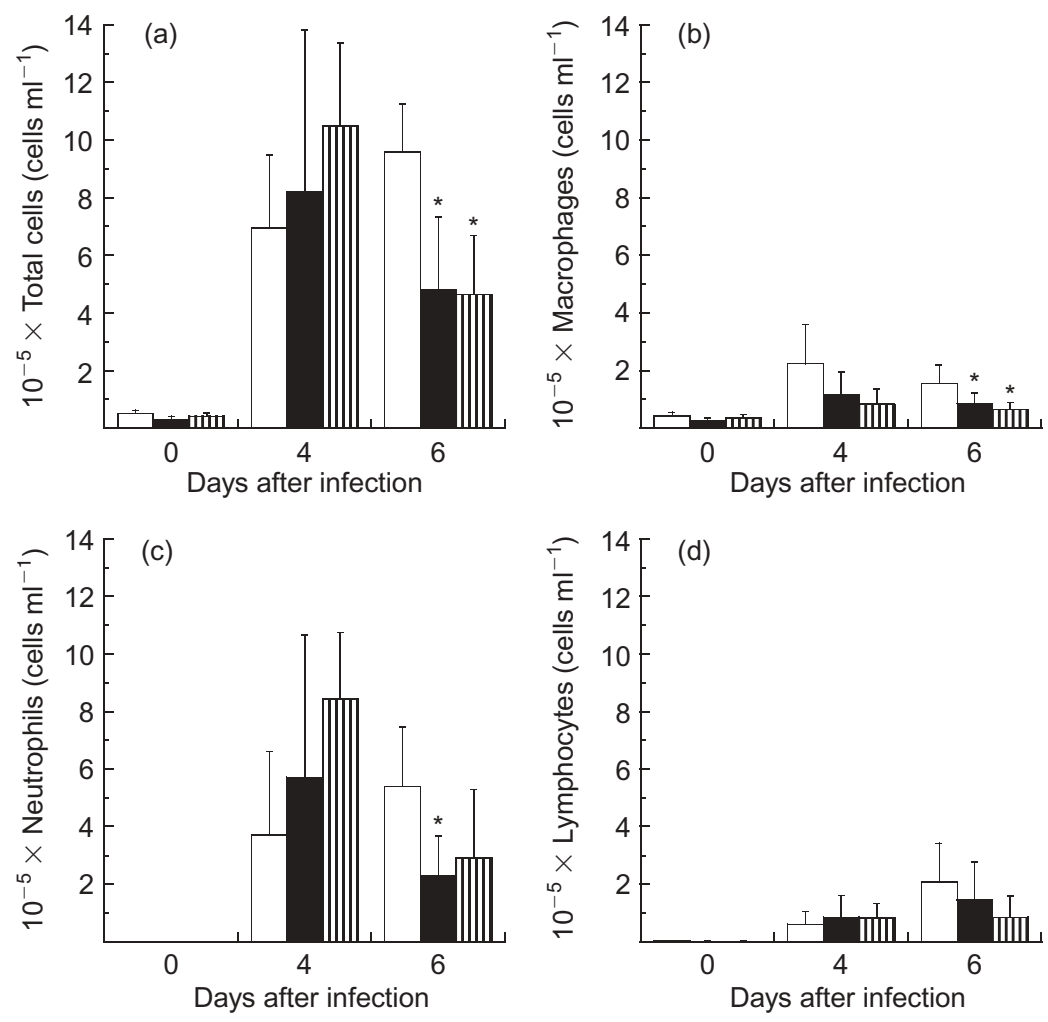

Fig. 3. Effects of LF and LPO on the number of infiltrated cells in the BALF of influenza-virusinfected mice. Water (open bars), LF (closed bars) or LPO (striped bars) was administered once daily from 1 day before infection until 1 day before sacrifice. The total number of cells (a) was determined using a haematocytometer and the contents of macrophages (b), neutrophils (c) and lymphocytes (d) were determined after DiffQuick staining. The data represent the mean cell number $\pm S D$ of six mice in experiment 1 . ${ }^{*} P<0.05$ vs water control. 
immunity of the host was not suppressed by the administration of LF and LPO. We are currently unaware of the mechanism of action of orally administered LF and LPO on the inflammatory cells in the lung. One possible mechanism for this could involve these proteins or their digested products indirectly modulating the systemic immune system by affecting gut-associated lymphoid tissue. From this point of view, it is of interest that oral administration of LF has been shown to enhance production of cytokines such as IL-18 and increase the numbers of many types of immune cells in the small intestine of mice (Wang et al., 2000). Another possible mechanism could involve small peptides generated from LF and LPO in the gastrointestinal tract exhibiting systemic effects after absorption into circulation. Further studies focusing on the metabolism and mechanism of action of orally administered LF and LPO should be conducted.

\section{Effects of LF and LPO on the production of cytokines}

We examined the effects of LF and LPO on cytokine production in the influenza-virus-infected mice. The levels of IFN- $\gamma$ (Fig. 4a) and IL-6 (Fig. 4c) detected in the BALF of the control mice were induced by the infection and markedly increased in a time-dependent manner until day 6. The level of IL-12 detected in the BALF of the control mice (Fig. 4b) was also induced on day 4 after infection, but had returned to the baseline by day 6 . No significant differences in the levels of IFN- $\gamma$, IL-12 and IL- 6 in the BALF were observed among groups at any time point. However, IL-6 levels in the BALF on day 6 tended to be lower in the mice given LPO than the control mice $(P=0 \cdot 076)$. The level of IL- 6 was also increased in the serum due to the infection (Fig. 4d). No significant difference in the serum IL-6 level was observed between the mice given LF and the control mice. On the other hand, mice given LPO showed a significantly lower serum IL-6 level compared with the control mice on day $6(P=0 \cdot 035)$.

Influenza virus infection causes elevated production of a wide range of cytokines and chemokines including IL-1, IL-6, IL-8, IL-10, TNF- $\alpha$, IFN- $\alpha / \beta$, IFN- $\gamma$ and MIP- $1 \alpha / \beta$ (Conn et al., 1995; Kaiser et al., 2001; Mogensen \& Paludan, 2001). Fever and body weight loss caused by influenza virus infection is slightly reduced in mice lacking the IL- 6 gene compared with wild-type mice, indicating that this proinflammatory cytokine partly contributes to the pathogenesis of the influenza virus infection (Kozak et al., 1997). In the present study, a significant positive correlation $(r=0.66$, $P<0 \cdot 01$ ) between the serum IL-6 levels and lung consolidation scores was observed on day 6 (Fig. 5).

LF has been reported to suppress the production of IL-6 and other pro-inflammatory cytokines when administered orally in animal models, including mice with bacterial urinary tract infections and rats with chemically induced colitis (Haversen et al., 2000; Togawa et al., 2002). It has been reported in vitro that LF down-regulates the production of IL- 6 and other proinflammatory cytokines in LPS-stimulated monocytic cells at the transcriptional level by interfering with the activation of nuclear transcription factor kappa B, a pleiotropic mediator of immune and inflammatory responses (Haversen et al.,
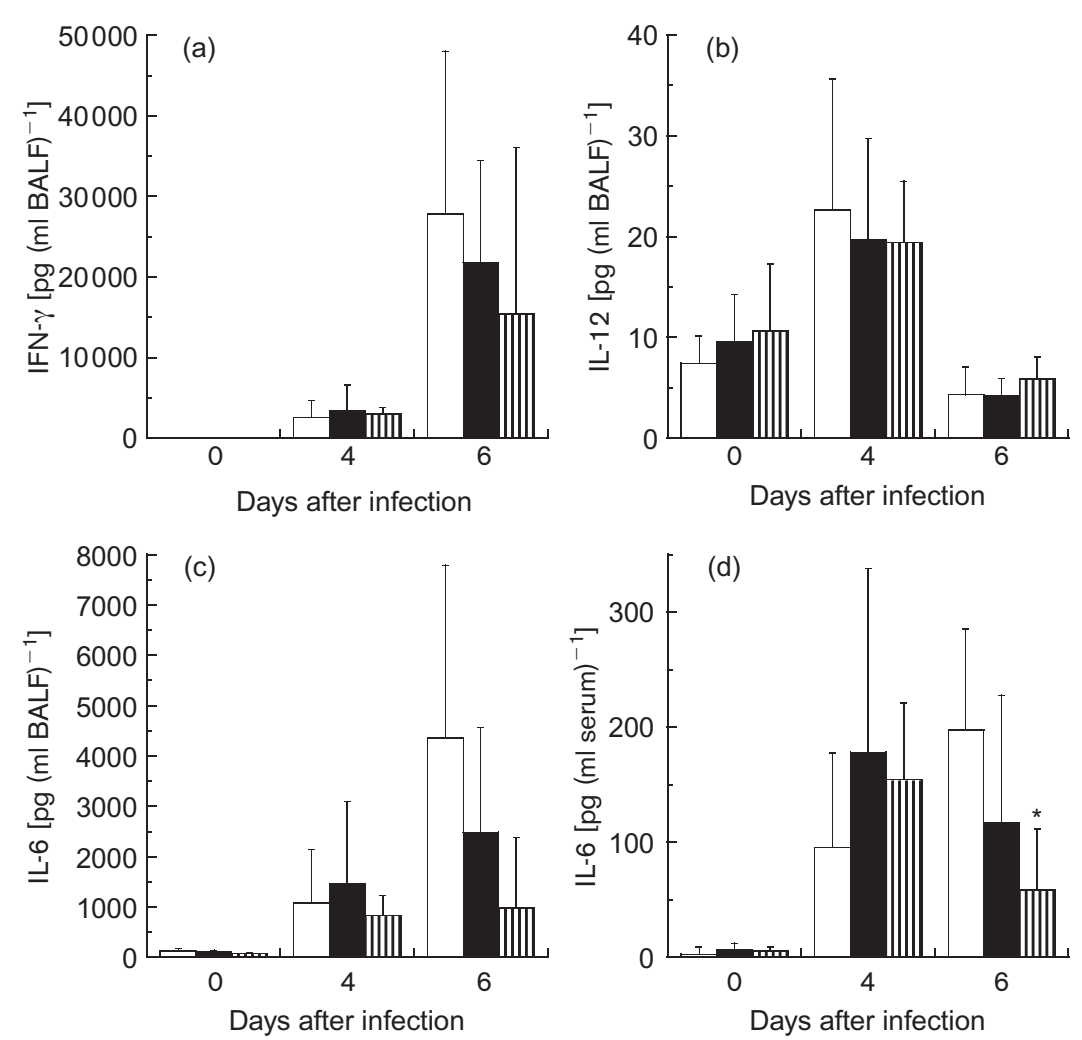

Fig. 4. Effects of LF and LPO on the cytokine levels in the BALF and serum of influenza-virusinfected mice. Water (open bars), LF (closed bars) or LPO (striped bars) was administered once daily from 1 day before infection until 1 day before sacrifice. The concentrations of IFN- $\gamma(a)$, $\mathrm{IL}-12$ (b) and IL-6 (c) in the BALF and IL-6 in serum (d) were measured by ELISA. The data represent the mean cytokine levels \pm SD of six mice in experiment $1 .{ }^{*} P<0.05$ vs water control. 


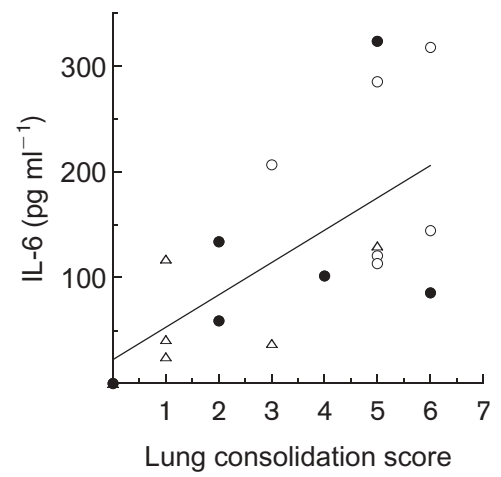

Fig. 5. Correlation between serum IL-6 level and the lung consolidation score on day 6 after infection. Water $(\bigcirc), \operatorname{LF}(\bullet)$ or LPO $(\triangle)$ was administered once daily from 1 day before infection until 5 days after infection in experiment 1. A significant positive correlation $(r=0.66$, $P<0.01$ ) between serum IL-6 levels and the lung consolidation score was shown with the Pearson correlation.

2002). In the current study, however, the suppressive effect of orally administered LF on the production of IL-6 was not observed in influenza-virus-infected mice. On the other hand, the serum level of IL- 6 on day 6 significantly decreased in mice given LPO compared with control mice (Fig. 4d). IL6 seems likely to be a possible new biomarker that is downregulated by LPO. Further studies focusing on the effect of LPO on the production of IL-6 will be required to more clearly understand the mechanism behind the immunomodulatory action of LPO.

In another experiment, we compared the survival rates of the mice given LF and the control mice using 20 animals in each group. By 14 days after infection, two and four of the mice had died in the groups given LF and the control, respectively. No significant difference was found in the survival rates between these two groups due to the low frequency of dead animals in the control group $(P=0.379$ by the log-rank test, details not shown). The survival rates of the mice given LPO and the control mice were not compared.

Milk contains various components with physiological significance for new-born animals. Recent progress in the technology of protein purification enables the production of biologically active milk proteins on an industrial scale. The application of milk proteins for the purpose of health promotion has gathered much attention (Cross \& Gill, 1999; Hooijdonk et al., 2000; Floris et al., 2003). Bovine LF and LPO are both purified from cheese whey with cationexchange chromatography and are now commercially available.

In conclusion, the present study demonstrated for the first time the beneficial effects of orally administered LF and LPO in influenza-virus-infected mice. LF and LPO were shown to attenuate pneumonia by suppressing the infiltration of inflammatory cells in the lung. LPO was further shown to reduce body weight loss and the production of a pro- inflammatory cytokine. These findings suggest the potential for LF and LPO as functional milk components to be used in the treatment of infections in which a hyper-reaction of host inflammatory responses is responsible for pathogenesis.

\section{REFERENCES}

Conn, C. A., McClellan, J. L., Maassab, H. F., Smitka, C. W., Majde, J. A. \& Kluger, M. J. (1995). Cytokines and acute phase response to influenza virus in mice. Am J Physiol 268, R78-R84.

Conner, G. E., Salathe, M. \& Forteza, R. (2002). Lactoperoxidase and hydrogen peroxide metabolism in the airway. Am J Respir Crit Care Med 166, S57-S61.

Cross, M. L. \& Gill, H. S. (1999). Modulation of immune function by a modified bovine whey protein concentrate. Immunol Cell Biol 77, 345-350.

Deliyannis, G., Jackson, D. C., Ede, N. J., Zeng, W., Hourdakis, I., Sakabetis, E. \& Brown, L. E. (2002). Induction of long-term memory $\mathrm{CD} 8^{+} \mathrm{T}$ cells for recall of viral clearing responses against influenza virus. J Virol 76, 4212-4221.

Di Mario, F., Aragona, G., Bo, N. D. \& 7 other authors (2003). Use of lactoferrin for Helicobacter pylori eradication. Preliminary results. J Clin Gastroenterol 36, 396-398.

Floris, R., Recio, I., Berkhout, B. \& Visser, S. (2003). Antibacterial and antiviral effects of milk proteins and derivatives thereof. Curr Pharm Des 9, 1257-1275.

Hashiba, T., Suzuki, M., Nagashima, Y., Suzuki, S., Inoue, S., Tsuburai, T., Matsuse, T. \& Ishigatubo, Y. (2001). Adenovirus-mediated transfer of heme oxygenase- 1 cDNA attenuates severe lung injury induced by the influenza virus in mice. Gene Ther 8, 1499-1507.

Haversen, L. A., Engberg, I., Baltzer, L., Dolphin, G., Hanson, L. A. \& Mattsby-Baltzer, I. (2000). Human lactoferrin and peptides derived from a surface-exposed helical region reduce experimental Escherichia coli urinary tract infection in mice. Infect Immun 68, 5816-5823.

Haversen, L., Ohlsson, B. G., Hahn-Zoric, M., Hanson, L. A. \& MattsbyBaltzer, I. (2002). Lactoferrin down-regulates the LPS-induced cytokine production in monocytic cells via NF- $\kappa$ B. Cell Immunol 220, 83-95.

Hooijdonk, A. C. M. V., Kussendrager, K. D. \& Steijns, J. M. (2000). In vivo antimicrobial and antiviral activity of components in bovine milk and colostrum involved in non-specific defence. Br J Nutr 84, S127S134.

Ishii, K., Takamura, N., Shinohara, M., Wakui, N., Shin, H., Sumino, Y., Ohmoto, Y., Teraguchi, S. \& Yamauchi, K. (2003). Long-term followup of chronic hepatitis $C$ patients treated with oral lactoferrin for 12 months. Hepatol Res 25, 226-233.

Kaiser, L., Fritz, R. S., Straus, S. E., Gubareva, L. \& Hayden, F. G. (2001). Symptom pathogenesis during acute influenza: interleukin-6 and other cytokine responses. J Med Virol 64, 262-268.

Kawasaki, Y., Isoda, H., Shinmoto, H., Tanimoto, M., Dosako, S., Idota, T. \& Nakajima, I. (1993). Inhibition by $\kappa$-casein glycomacropeptide and lactoferrin of influenza virus hemagglutination. Biosci Biotechnol Biochem 57, 1214-1215.

Kozak, W., Poli, V., Soszynski, D., Conn, C. A., Leon, L. R. \& Kluger, M. J. (1997). Sickness behavior in mice deficient in interleukin-6 during turpentine abscess and influenza pneumonitis. Am J Physiol 272, R621R630.

Kurokawa, M., Ochiai, H., Nakajima, K. \& Niwayama, S. (1990). Inhibitory effect of protein kinase $\mathrm{C}$ inhibitor on the replication of influenza type A virus. J Gen Virol 71, 2149-2155.

Lefkowitz, D. L., Lefkowitz, S. S., Mone, J. \& Everse, J. (1988). Peroxidase-induced enhancement of chemiluminescence by murine peritoneal macrophages. Life Sci 43, 739-745. 
Lefkowitz, D. L., Hsieh, T.-C., Millis, K. \& Castro, A. (1990). Induction of tumor necrosis factor and cytotoxicity by macrophages exposed to lactoperoxidase and microperoxidase. Life Sci 47, 703-709.

Lönnerdal, B. \& lyer, S. (1995). Lactoferrin: molecular structure and biological function. Annu Rev Nutr 15, 93-110.

Maeda, H. \& Akaike, T. (1991). Oxygen free radicals as pathogenic molecules in viral diseases. Proc Soc Exp Biol Med 198, 721-727.

Mikola, H., Waris, M. \& Tenovuo, J. (1995). Inhibition of herpes simplex virus type 1 , respiratory syncytial virus and echovirus type 11 by peroxidase-generated hypothiocyanate. Antiviral Res 26, 161-171.

Mogensen, T. H. \& Paludan, S. R. (2001). Molecular pathways in virusinduced cytokine production. Microbiol Mol Biol Rev 65, 131-150.

Mori, K., Kido, T., Daikuhara, H., Sakakibara, I., Sakata, T., Shimizu, K., Amagaya, S., Sasaki, H. \& Komatsu, Y. (1999). Effect of Hochu-ekki-to (TJ-41), a Japanese herbal medicine, on the survival of mice infected with influenza virus. Antiviral Res 44, 103-111.

Pourtois, M., Binet, C., Tieghem, N. V., Courtois, P., Vandenabbeele, A. \& Thiry, L. (1990). Inhibition of HIV infectivity by lactoperoxidaseproduced hypothiocyanite. J Biol Buccale 18, 251-253.

Reiter, B., Marshall, V. M. \& Philips, S. M. (1980). The antibiotic activity of the lactoperoxidase-thiocyanate-hydrogen peroxide system in the calf abomasum. Res Vet Sci 28, 116-122.

Sidwell, R. W., Huffman, J. H., Bailey, K. W., Wong, M. H., Nimrod, A. \& Panet, A. (1996). Inhibitory effects of recombinant manganese superoxide dismutase on influenza virus infections in mice. Antimicrob Agents Chemother 40, 2626-2631.

Takakura, N., Wakabayashi, H., Ishibashi, H., Yamauchi, K., Teraguchi, S., Tamura, Y., Yamaguchi, H. \& Abe, S. (2004). Effect of orally administered bovine lactoferrin on the immune response in the oral candidiasis murine model. J Med Microbiol 53, 495-500.

Tanaka, K., Ikeda, M., Nozaki, A., Kato, N., Tsuda, H., Saito, S. \& Sekihara, H. (1999). Lactoferrin inhibits hepatitis $C$ virus viremia in patients with chronic hepatitis C: a pilot study. Jpn J Cancer Res 90, 367-371.
Tenovuo, J. (2002). Clinical applications of antimicrobial host proteins lactoperoxidase, lysozyme and lactoferrin in xerostomia: efficacy and safety. Oral Dis 8, 23-29.

Togawa, J., Nagase, H., Tanaka, K., Inamori, M., Nakajima, A., Ueno, N., Saito, T. \& Sekihara, H. (2002). Oral administration of lactoferrin reduces colitis in rats via modulation of the immune system and correction of cytokine imbalance. J Gastroenterol Hepatol 17, 12911298.

Tsurita, M., Kurokawa, M., Imakita, M., Fukuda, Y., Watanabe, Y. \& Shiraki, K. (2001). Early augmentation of interleukin (IL)-12 level in the airway of mice administered orally with clarithromycin or intranasally with IL-12 results in alleviation of influenza infection. J Pharmacol Exp Ther 298, 362-368.

van der Strate, B. W. A., Beljaas, L., Molema, G., Harmsen, M. C. \& Meijer, D. F. K. (2001). Antiviral activities of lactoferrin. Antiviral Res 52, 225-239.

Vorland, L. H. (1999). Lactoferrin: a multifunctional glycoprotein. APMIS 107, 971-981.

Wakabayashi, H., Kurokawa, M., Shin, K., Teraguchi, S., Tamura, Y. \& Shiraki, K. (2004). Oral lactoferrin prevents body weight loss and increases cytokine responses during herpes simplex virus type 1 infection of mice. Biosci Biotechnol Biochem 68, 537-544.

Wang, W., ligo, M., Sato, J., Sekine, K., Adachi, I. \& Tsuda, H. (2000). Activation of intestinal mucosal immunity in tumor-bearing mice by lactoferrin. Jpn J Cancer Res 91, 1022-1027.

Wong, C. W., Regester, G. O., Francis, G. L. \& Watson, D. L. (1996). Immunomodulatory activities of whey fractions in efferent prefemoral lymph of sheep. J Dairy Res 63, 257-267.

Wong, C. W., Seow, H. F., Husband, A. J., Regester, G. O. \& Watson, D. L. (1997). Effects of purified bovine whey factors on cellular immune functions in ruminants. Vet Immunol Immunopathol 56, 85-96.

Yamauchi, K., Hiruma, M., Yamazaki, N., Wakabayashi, H., Kuwata, H., Teraguchi, S., Hayasawa, H., Suegara, N. \& Yamaguchi, H. (2000). Oral administration of bovine lactoferrin for the treatment of tinea pedis. A placebo-controlled, double-blind study. Mycoses 43, 197-202. 